\title{
A Europa culta e o maravilhoso deserto
}

Celina Maria Moreira de Mello I UFRJ

Ao querido Professor e amigo, Afonso Marques dos Santos.

Resumo: O presente ensaio propõe uma reflexão sobre o tema das relações entre a literatura francesa e a literatura brasileira, à luz dos vinculos entre literatura e nação, na perspectiva de uma formação discursiva moderna. As literaturas nacionais projetam-se no espaço da literatura mundial, onde estão sujeitas às mesmas regras de competição que definem as relaçōes entre as naçôes. Embora os processos político-econômicos de povoamento e ocupação dos territórios, no Brasil, não suportem comparaçōes com os que ocorrem na França, em ambos os paises a literatura se constitui como sistema que produz e faz circular novas formas de capital simbólico, identificaçôes imaginárias e modelos linguísticos hegemônicos. Evocamos a Missão Francesa, para lembrar que se trata de uma educação do olhar. Também será mencionada a descrição de personagens, enfatizando sua função de produção e reforço de uma imagem de tipos nacionais. Palavras-chave: Literaturas nacionais, romantismo, Missão Francesa.

1. FOUCAULT. L'archéologie du savoir. 
O Brasil apenas conbecido na Europa culta como um vasto e maravilhoso deserto habitado por selvagens antropophagos, começa em fim a merecer a attenção que justamente reclama sua cathegoria social.

$\bigcirc$ presente ensaio pretende trazer alguns elementos de reflexão sobre o tema das relações entre a literatura brasileira e a literatura francesa, propondo um outro olhar sobre os clichês, que já parecem inevitáveis, de imitações ou influências, e seu bizarro séquito imaginário, em que alternam mesmerização e estranheza. Este desvio do olhar nos leva à investigação dos modos de constituição do fenômeno literário, considerando sua inserção no tempo, com um aprofundamento de sua dimensão histórica moderna. Pois, nossa linha de investigação da Literatura francesa do século XIX, informada por uma leitura foucaultiana da História, tem sido a de considerar que o romantismo instaura uma nova formação discursiva, a qual produz um espaço-histórico em que se insere a literatura enquanto sistema. ${ }^{3}$ Nesta perspectiva, a literatura brasileira e a literatura francesa teriam a mesma idade, se compreendidas à luz dos vínculos entre literatura e nação, nos Estados modernos.

\section{Descontinuidades opacas e literaturas nacionais}

Podemos falar hoje de um espaço literário internacional? Para Pascale Casanova, ${ }^{4}$ o espaço literário internacional foi criado no século XVI, na Europa. A literatura do século XIX, vista enquanto sistema de gêneros moderno, aparece em uma certa doxa de história literária como resultando de uma linha evolutiva no sentido do progresso. Contudo, na esteira de Foucault, em As palavras e as coisas (1966), parece ser produtivo pensar uma descontinuide entre epistemes que se

2. D. J. G. de Magalhães. Nitheroy; Revista Brasiliense. Sciencias, Letras E Artes.

3. Notas metodológicas vinculadas ao projeto de pesquisa "Do literário \& do prosaico; interrogações sobre o realismo", desenvolvido com apoio do CNPq.

4. Cf. CASANOva. La République Mondiale des Lettres, p. 25. 
sucedem no tempo, as quais projetam dois sistemas distintos de produção escrita, socialmente valorizados, o sistema das Belas-letras e o sistema da Literatura. ${ }^{6}$

Na periodização de história geral proposta por Foucault, em As palavras $e$ as coisas (1966), que definia uma episteme neoclássica, nos séculos XVII-XVIII, e uma episteme moderna, ou seja, romântica, nos séculos XIX-XX, vemos rompida a unidade da História que se vai fragmentar em um espaço de dispersão das histórias. Entre a episteme neoclássica e a episteme moderna, uma relação de descontinuidade vem redimensionar a oposição hegeliana, historicamente construída, entre clássico e romântico.

Em um primeiro momento, que corresponde para Foucault à episteme do Renascimento, não haveria como afirmar realidades internacionais. O que existe é um espaço-histórico europeu, em que se constituem os Estados modernos, a partir de processos de unificação, centralização política e administrativa e laicização dos centros de poder, bem delimitados. Constituição para a qual contribuem modos "estetizados" de conferir visibilidade, prestígio e legitimação aos donos do poder, os monarcas hereditários, por meio dos diversos modos de expressão artística. Forma-se, na relação entre um conjunto de obras, as instituições que as legitimam e os círculos de poder político, o sistema das Belas-letras, que vem transpor, nas línguas vernaculares, um sistema de gêneros codificados pelas poéticas clássicas, cuja tradição remonta à Antiguidade greco-latina.

A fruição das obras escritas em vernáculo é o privilégio de grupos reduzidos e estas devem sua existência a um sistema de mecenato, à proteção do príncipe. Descarta-se, neste sistema, uma produção escrita europeia em latim,

5. Cf. FOUCAUlt. Les mots et les choses.

6. "Ao comparar o sistema das Belas-letras e o sistema da Literatura, vê-se que se trata de dois sistemas distintos. Não se pode afirmar nem que o primeiro gerou o segundo, nem que ambos se opõem termo a termo, como se a Literatura tivesse substituído as Belas-letras, com a lógica do 'rei morto, rei posto'”. MELLO. L'Artiste (1831-1838); crítica literária, ethos e cena genérica.

7. MELLO. Por um novo olhar sobre um saber antigo; o estatuto do clássico no espaço-histórico francês, p. 40. 
resultante de uma "herança latina", do mesmo modo que os soberanos desses estados lutam para escapar ao controle político do Papa.

Embora o conceito de episteme desapareça da Arqueologia do saber (1969), a questão metodológica que atravessa a obra de Foucault, a qual passa a privilegiar as práticas discursivas, mantém como interrogação as descontinuidades. E Foucault nos adverte sobre a dificuldade de se voltar o olhar para o passado, informado por categorias que são nossas e que projetamos em outras épocas por um processo de hipóteses retrospectivas, em um "jogo de analogias formais":

Nós mesmos não temos certezas sobre os usos destas distinções [dos grandes tipos de discursos, formas e gêneros] no mundo de discurso que é o nosso. Quanto mais quando se trata de analisar conjuntos de enunciados que, à época de sua formulação, eram distribuídos, repartidos e caracterizados de um modo totalmente diverso: afinal de contas a "literatura" e a "política" são categorias recentes que só podem ser aplicadas à cultura medieval ou ainda à cultura clássica por meio de uma hipótese retrospectiva, e por um jogo de analogias formais ou de semelhanças semânticas; mas nem a literatura, nem a política, nem a filosofia e as ciências, nos séculos XVII ou XVIII, articulavam o campo do discurso, como o articularam no século XIX.

Como observa Jacques Le Goff, a periodização que usamos é muito recente, data do século XIX:

A periodização que ainda usamos (476-1492) é portanto muito recente. Vem do século XIX. Responde às necessidades de um ensino escolar e universitário em expansão. Esse ensino tem necessidade de datas, de quadros, de balizas. Quer-se estruturar - e isso não é mau. Mas essa estruturação nunca é inocente. O grande negócio era menos datar o fim da Antigüidade do que demarcar ou balizar a Idade Média e estabelecer o começo do mundo moderno, com o Renascimento. ${ }^{10}$

8. "A Idade Média foi antes de tudo latina: consideramos, entretanto, grosseira a cultura latina, sobretudo o chamado latim "da Igreja". LE GOFF. Em busca da Idade Média, p. 64.

9. FOUCAUlT. L'archéologie du savoir, p. 33. Traduções da autora, exceto quando explicitamente referido.

10. LE GOFF. Em busca da Idade Média, p. 63-64. 
Os marcos que estruturam nossa visão do passado resultam, pois, de representações de uma continuidade em progresso, da formação de um Estado unificado, que projetaria a soberania de uma nação, em um arco temporal imaginário, que se legitima, a um só tempo, pelas suas origens, suas raízes, por seus traços identitários e por seu projeto. Unidade linguística e étnica, singularidade identitária e continuidade temporal são portanto constructos culturais.

Os Estados modernos, nos séculos XVII e XVIII, e, de certo modo, ainda ao longo do século XIX, são atravessados por fraturas sociais, econômicas e linguísticas entre a identidade coletiva das camadas dominantes, que se homogeneízam por mecanismos de aliança e emulação, e a ambientação cultural obscurantista e supersticiosa de grupos isolados de camponeses iletrados. Ora, compreender esta ambientação cultural nos exige um esforço de reconstituição. O historiador Roger Chartier, ao percorrer a noção de civilidade e os livros que a veiculam, pontua tal dificuldade, que identificamos, igualmente, quando se trata de literatura:

Tentar compreender o que os homens, entre os séculos XVI e XVII, entendiam por civilidade é, pois, entrar no coração de uma sociedade antiga, que muitas vezes nos é opaca, em que as formas sociais são representações codificadas das categorias e das condições em que muitos comportamentos por longo tempo publicamente lícitos tornam-se proibidos, mesmo no refúgio do privado. ${ }^{11}$

O recorte institucional e um imaginário coletivo eurocêntrico, no século XIX, ao consolidar processos que já se esboçam nas últimas décadas do século XVIII e que marcam o que Eric J. Hobsbawm aponta como "a era das revoluções", ${ }^{12}$ identificam uma nação, uma língua, um povo, um território e uma literatura, atribuindo-lhes um caráter único que será chamado de "nacional". Ao longo do século XIX, as obras que ilustram as literaturas nacionais e operam como realizações de uma dada coletividade são vistas como "singulares", expressando o gênio, que passa muito facilmente de "engenho" a "genialidade", de indivíduos singulares que figuram então como os representantes do brilho e das capacidades de um povo, de que se orgulham seus "nacionais". Cria-se uma equivalência,

11. CHARTIER. Leituras e leitores na França do Antigo Regime, p. 45.

12. Cf. HobsBawm. A era das revoluções; Europa 1789-1848. 
dramática para muitos países, que hoje chamamos de periféricos, ${ }^{13}$ entre Literatura, Arte, riquezas e glória nacionais. E as diferenças entre as sociedades deixam de ser explicadas pela vontade divina, para serem atribuídas a um direito "natural", decorrente da superioridade de certas etnias.

As dificuldades para dar conta dos processos de formação, autonomia e interrelação das literaturas nacionais, sem cair nas armadilhas de periodizações simplificadoras ou em imaginários de um qualquer "direito de existência literária", podem ser enfrentadas pelo recurso ao conceito foucaultiano de formação discursiva. Este, fortalecido por um redimensionamento ideológico operado por Pêcheux, é definido por Dominique Maingueneau como: "conjunto de enunciados sociohistoricamente circunscrito que pode ser referido a uma identidade enunciativa". ${ }^{16}$

A formação discursiva romântica mascara o fato de que as obras que foram realizadas por artistas do panteão nacional, mais do que constituírem um reflexo do engenho de um artista ou de um povo, encontram-se em uma relação de competição e ressonância com outras literaturas nacionais e, de uma maneira ou de outra, transcendem os limites que lhes são impostos, projetando-se no espaço da literatura mundial, onde estão sujeitas às mesmas regras que definem as relações entre as nações, no que se refere a poder e prestígio.

Sem a pretensão de reconstituirmos a gênese dos movimentos políticos e sociais que explodem na Revolução Francesa, evocamos as transformações das estruturas econômicas, que são inseparáveis do movimento de constituição de literaturas nacionais, da ideia de nação e das questões linguísticas envolvidas. $O$ século XIX, na França, vê acelerar-se o fenômeno do êxodo rural, que obriga o homem do campo a aprender a se inserir na urbe, a ser e circular neste novo

13. Cf. GUIMARÃES. Quinhentos anos de periferia.

14. Cf. GuIMARÃES. Quinhentos anos de periferia, p. 31.

15. "Os movimentos nacionalistas que surgiram na Europa Central no decorrer do século XIX favoreceram a manifestação de novas reivindicações ao direito de existência literária. A América do Norte e a América Latina também entraram aos poucos na disputa no decorrer do século XIX; enfim, com a descolonização, todos os países até então excluídos da idéia mesma de literatura própria (na África, na Índia, na Ásia...) reivindicaram o acesso à legitimidade e à existência literárias." CASANOVA. La République Mondiale des Lettres, p. 25-26.

16. MAINGUENEAU. Formation discursive, p. 271. Ver a este respeito, igualmente, MAINGUENEAU. Archéologie et analyse du discours. 
espaço, a aprender um novo modo de habitar seu corpo, na urbanidade. Embora os processos político-econômicos de povoamento e ocupação dos territórios, no Brasil, não suportem, evidentemente, comparações, com os que ocorrem na França, em ambos os países a literatura se constitui como sistema que produz e faz circular novas formas de capital simbólico, identificações imaginárias e modelos linguísticos hegemônicos.

Ao nos referirmos a uma França Antigo Regime e uma França no século XIX, a palavra França projeta a ilusão de uma coincidência lugar/povo/ língua/cultura, análoga à que se instaura, com a palavra Brasil, quando se evoca o Brasil-Colônia e Brasil-Império. Por outro lado, as imagens de uma França pósrevolução e de um Brasil pós-independência, resultam de mecanismos políticos e discursivos comparáveis. E a moderna ideia de nação, vinculada a um tipo de governo que se legitima ao fundar-se no povo, pressupõe uma identidade única, nacional, neste caso, a do povo francês ou a do povo brasileiro, que sobredeterminaria o sistema de representações coletivas. Pois uma urgente questão política se coloca: como renovar e controlar o capital simbólico? ou seja, como fazer de agrupamentos de populações, até então dispersos, o fundamento e o princípio do governo cujo poder dele emana?

Destacamos, com Eric J. Hobsbawm, a relação entre nação, Estado, povo e território. E a dificuldade de conciliar o ideário revolucionário do povo como corpo de cidadãos, representando "o interesse comum contra os interesses particulares", com "o programa posterior de estabelecer Estados-nações para corpos (sociais) definidos em termos dos critérios tão intensamente debatidos pelos teóricos do século XIX, tais como etnicidade, língua comum, religião, território e lembranças históricas". 17

O historiador Schlomo Sand observa que o desenvolvimento dos Estados-nações dá forma a uma política identitária, cuja plasticidade "levou a apagar completamente as profundas diferenças entre o antigo mundo agrário e o novo universo industrial e comercial no qual ainda vivemos em nossos dias". ${ }^{18}$ Sua história resulta de um formidável movimento de apropriação de memórias fragmentárias e desconexas, cujo eixo central era fundamentalmente de cunho religioso, para conferir-lhe uma dimensão política. Tais fragmentos são reescritos para conferir

17. HOBSBAWM. Nações e nacionalismo desde 1870.

18. SAND. Comment le peuple juif fut inventé; de la Bible au sionisme. 
um passado, um rosto, um corpo, uma voz e um destino a um povo. Apaga-se a memória de um antes e um depois, para construir uma linearidade temporal que se quer em progresso e de fundo teleológico. O passado reinventado será indicador da estrada para o futuro.

Foucault chamara a atenção para tais imaginários que suturam a hiância constitutiva do sujeito, acentuando sua dispersão e descontinuidade em relação a si próprio, o que desconstrói, em seu tempo, a subjetividade do indivíduo, o sujeito cartesiano e o sujeito da História:

O discurso, considerado deste modo, não é a manifestação, que desfila com majestade, de um sujeito que pensa, que conhece e que diz tal: ao contrário, trata-se de um conjunto em que podem ser determinadas a dispersão do sujeito e sua descontinuidade em relação a si próprio. Ele é um espaço de exterioridade em que se desdobra uma rede de deslocamentos distintos. Mostramos anteriormente que não era nem pelas "palavras" nem pelas "coisas" que se devia definir o regime dos objetos que são próprios de uma formação discursiva; do mesmo modo, é preciso agora reconhecer que não é recorrendo a um sujeito transcendental nem pelo recurso a uma subjetividade psicológica que devemos definir o regime de suas enunciações. ${ }^{19}$

Diante dos processos nacionais unificadores, como entender o "espaço de dispersão" da arqueologia foucaultiana? As formações discursivas, em a Arqueologia do saber, operaram como um recurso metodológico para que Foucault se aproximasse da História, sem abrir mão das novas perspectivas abertas pelo estruturalismo. São redesenhados os limites entre as abordagens estruturais de base linguística e o tratamento marxista da História e da praxis. As inovadoras noções de prática discursiva, assim como as de relações discursivas ${ }^{20}$ vão possibilitar uma reflexão necessária sobre os limites entre o que é da ordem do discurso e um impossível espaço de exterioridade. Aproximar-se da História para levantar traços de regularidade em um espaço de dispersão é o trabalho do arqueólogo: construir uma rede de relações, que para o estruturalista são sincrônicas, projetando-as na

19. FOUCAUlT. L'archéologie du savoir, p. 74.

20. Para melhor compreensão da perspectiva proposta, remetemos ao conceito de interdiscurso: "conjunto de discursos (...) que mantêm relações de delimitação recíproca entre si". MAINGUENEAU. Interdiscours, p. 324. 
diacronia, cortando-as de questões de origem e fundação, espacializando-as. Procedimento metodológico em que o arquéologo opera cortes que oferecem ao olhar diversas camadas, que podem ser comparadas às diferentes camadas geológicas, onde "subitamente o espaço e o tempo se confundem; a densidade viva do instante justapõe e perpetua as eras".

Em um projeto de leitura do romantismo, na perspectiva de uma formação discursiva moderna, explora-se um recorte que possibilite construir um espaço-histórico em que ainda coexistam programas estéticos, cenas genéricas e arsenais retóricos diversos. E projeta-se a Literatura enquanto sistema de valores constituindo-se em tensão com o sistema das Belas-letras. Assim, para ilustrar as afirmações que precedem, vamos evocar a Missão Francesa, sempre lembrada quando se trata de discutir a identidade nacional, procurando um olhar não ofuscado pela formidável operação de acumulação e apropriação de capital simbólico que faria da França um modelo para a literatura brasileira. ${ }^{22}$ Pois que se trata de uma educação do olhar. Também será mencionada, rapidamente, a importância da descrição de personagens, enfatizando sua função de produção e reforço de uma imagem dos traços físicos e gestuais de tipos nacionais.

\section{Onde está o povo?}

Em 1822, no momento de sua independência, o Brasil vive a importação de um projeto estético associado a um projeto político civilizatório. $O$ historiador Afonso Marques dos Santos afirma: "Tratava-se de construir o que em outras oportunidades chamamos de "Europa possível", desenvolvendo um projeto civilizatório que acompanhasse a montagem política do Estado Imperial ." 23

Em 1816, ao convidar e contratar, para uma missão civilizatória, um grupo de pintores, arquitetos, escultores, e também um mecânico, um serralheiro e carpinteiros - a chamada Missão Artística francesa - o príncipe português, futuro

21. LÉVI-STRAUSS. Tristes tropiques, p. 61.

22. Cf. A seção Paris, cidade-literatura, em CASANOVA. La République Mondiale des Lettres, p. 40.

23. SANTOS. A Academia Imperial de Belas Artes e o Projeto Civilizatório do Império, p. 128. 
Dom João VI, desencadeia um processo paradoxal. ${ }^{24}$ São artistas davidianos, formados nos princípios revolucionários da regeneração, ou seja, da importância da arte para a educação cívica do povo. Os modelos neoclássicos das Belas Artes, a volta a padrões estéticos da Roma antiga republicana e dos modelos de virtude guerreira de Esparta revestem-se, para eles, de uma significação política republicana. $O$ grupo de franceses vem ao Brasil a convite de um príncipe da família reinante, os Bragança, pouco sensível a seu ideário revolucionário, mas que deseja promover um processo pedagógico que pressupõe a laicização da arte e de seus valores políticos, em um sentido amplo.

O grupo, chefiado por Joachim Lebreton, "secretário perpétuo da classe de belas artes do Instituto de França", era integrado por Jean-Baptiste Debret, pintor de história; Nicolas-Antoine Taunay, pintor de paisagens e batalhas; Auguste Henri Victor Grandjean de Montigny, Charles Lavasseur e Louis Ueier, arquitetos; Auguste Marie Taunay e François Bonrepos, escultores; Charles Simon Pradier, gravador; François Ovide, mecânico; Jean Baptiste Level, ferreiro; Nicolas Magliori Enout, serralheiro; Pelite e Fabre, curtidores; Louis Jean Roy e seu filho Hypolite, carpinteiros. Seis meses depois chegariam os irmãos Marc e Zéphyrin Ferrez, o escultor e o gravador de medalhas.

O príncipe que os acolhe busca, nos artesãos, conhecimentos tecnológicos que possam ser ensinados em um Liceu de Artes e Ofícios. Dos artistas, espera uma produção que o legitime em seu poder e glória. Mas durante certo tempo sua única atividade estará voltada para a construção de cenários para as grandes festas reais, entre os quais três monumentos efêmeros para a Aclamação de Dom João VI como rei, em $1818 .^{26}$ Por circunstâncias históricas, com a

24. Quando a família real portuguesa chegou ao Rio de Janeiro, em 1808, o Brasil era colônia de Portugal. Em 1815, o Brasil foi proclamado "Reino", formando o Reino Unido de Portugal e Algarve. Dom João VI chegou ao Brasil como Príncipe regente e foi aclamado rei em 1818, tendo partido em 1821, retornando a Portugal como Rei de Portugal, do Brasil e do Algarve.

25. LUZ. Missão francesa.

26. Estes monumentos, infelizmente, não são representados na litografia de Debret, Vue de l'extérieur de la galerie de l'acclamation du Roi D. Jean VI (Cerimônia da Faustíssima Aclamação de S.M., o Senhor D. João VI, Rei do Reino Unido de Portugal e do Brasil e Algarves, celebrada no Rio de Janeiro em 6 de fevereiro de 1818), Aquarela monocromática (sépia), 23 x 30,5 cm, c. 1818, publicada em DEBRET. Voyage pittoresque et historique au Brésil, reproduzida em CARDOSO. Castro Maya colecionador de Debret, p. 29. 
Independência do Brasil, em 1822, os artistas da Missão Francesa se veem a serviço de um príncipe, o Imperador Pedro I, figura que encarna várias contradições.

O crítico de arte Rodrigo Naves, comenta o "descompasso da situação", nas festas de aclamação de Dom João VI, com a exclusão da população na festa aristocrática, bem diversa da participação do povo nas festas revolucionárias francesas:

Pela vivência acumulada, por tudo que tinham passado, dificilmente deixariam de notar com alguma clareza os lances extravagantes a que se viam obrigados, na tentativa de fazer resplandecer uma dinastia já sem brilho. Transformados em atributos de uma personagem senhorial e muito pouco modelar, os símbolos e episódios do passado perdiam todo o poder normativo que os caracterizava no neoclassicismo. Eles agora se distribuem a esmo, compondo uma narrativa alegórica descosida. (...) Além disso, a própria natureza da festa real excluía o grosso da população de uma participação mais esclarecida em seus rituais. (...) A festa revolucionária é a ocasião para se dar visibilidade a noções que galvanizam as forças populares. ${ }^{27}$

O programa estético neoclássico que é traçado e executado, na Academia Imperial de Belas Artes, apresenta, em tensão, o choque de habitus ${ }^{28}$ de diferentes grupos sociais, ocupando posições conflitantes no campo político. A estética "romana" de decoração das festas cívicas revolucionárias, que durante a Revolução Francesa visa estimular e ensinar a cidadania, serve à glória de um príncipe que ocupa o lugar do líder em função de privilégios hereditários. Do mesmo modo, a técnica de construção neoclássica do espaço arquitetônico e pictural, uma das marcas da estética davidiana, que também servira ao projeto romano civilizatório de Napoleão, será usada para a construção de um espaço metonímico de um rei-imperador, que os próprios artistas da Missão Francesa haviam educado na admiração pela figura histórica e mítica de Napoleão. Ao comparar o quadro de Jean Baptiste Debret, Coroação de Dom Pedro I (1828), com o quadro de JacquesLouis David, A coroação do imperador e da imperatriz(1805-1807), que representa

27. NAVES. A forma difícil; ensaios sobre a arte brasileira, p. 62-63.

28. Conceito proposto por Pierre Bourdieu e que se refere a um "sistema de disposições duráveis adquirido pelo indivíduo ao longo do processo de socialização que gerencia e organiza as práticas e as representações dos indivíduos e dos grupos". BONNEWITZ. Pierre Bourdieu; vie, œuvre, concepts, p. 94 . 
a coroação de Napoleão e Josefina, na Catedral de Notre-Dame, ${ }^{29}$ Rodrigo Naves pontua, ainda, a dificuldade que encontrara Debret, para executar um programa político revolucionário por meio da forma neoclássica, e acentua o acanhamento da cerimônia brasileira, assim como a impossibilidade, para a monarquia portuguesa de ocupar o espaço. ${ }^{30}$ Mas há um outro espaço que se abre no centro do quadro, com a técnica da veduta, recurso ausente do quadro de David, e que representa o porto do Rio de Janeiro. O céu azul e os navios ancorados, que são vistos ao fundo, evocam, a nosso ver, o laço que amarra (e aprisiona) aquela cerimônia a uma Europa distante e próxima, graças ao comércio marítimo. Mas também, indicam o grande tema da pintura moderna, que se desenvolverá no Brasil, a paisagem exótica, ausência/presença naquele quadro. Tema "natural" nestas paragens, nossas paisagens serão representadas como paradisíacas e abertas para o futuro, como que a compensar a inexistência de catedrais góticas que sirvam de cenário às cerimônias oficiais, como no quadro de David, ou que sejam o testemunho vivo de um glorioso passado medieval que possa dar lastro ao futuro da nação, e lustre a uma literatura nacional.

E o gênero do retrato oficial, cujas encomendas inexistem fora do círculo palaciano, será cultivado como a tradução brasileira de uma tradição genuinamente acadêmica, a serviço de um Estado que se quer moderno, e que se vê encarnado em seu príncipe. Mas estes artistas e todos aqueles que eles formaram também deverão estar a serviço de um projeto de construção de uma imagem de nação, projeto político que assistirá ao choque entre a estética davidiana neoclássica e a estética romântica colorista. A inflexão romântica que recebe, na França, a pintura de história, para encenar picturalmente o povo como protagonista da História, tal como vemos no célebre quadro de Delacroix, A liberdade conduzindo o povo, ${ }^{31}$ será traduzida, igualmente, no Brasil, por uma impossibilidade. O povo encenado é pitoresco, o espaço é exótico e torna-se melancólico.

29. Jean Baptiste Debret. Coroação de Dom Pedro I, 1828. Óleo s/ tela, $340 \times 640 \mathrm{~cm}$. Itamaraty, Brasília. Jacques-Louis David. Consagração do Imperador Napoleão I e Coroação da Imperatriz Josefinana Catedral de Notre-Dame de Paris, em 2 de Dezembro de 1804, 1806 e 1807. Óleo s/ tela, 621 x $979 \mathrm{~cm}$. Museu do Louvre, Paris, França.

30. NAVES. A forma difícil; ensaios sobre a arte brasileira, p. 64-65.

31. Eugène Delacroix. A liberdade conduzindo o povo, 1830. 260 × 325 $\mathrm{cm}$. Museu do Louvre, Paris. 
Aqui reside a grande aporia desta "missão civilizatória": a nação emana do povo, e onde está o povo, em um país de imigrantes e escravos? Rodrigo Naves ilustra tal impossibilidade, com a bela aquarela de Jean Baptiste Debret, $O$ primeiro impulso da virtude guerreira (1827), ${ }^{32}$ em que crianças pobres, negras, brancas e mulatas, brincam descalças de soldado, a cavalo sobre berimbaus, imitando uma parada militar:

(...) quando atentamos para o modo como a aquarela foi realizada, sobressai mais o afastamento em relação ao padrão francês do que a possibilidade de uma realização em terras coloniais. De saída, chama a atenção a total ausência de uma linha de força que dê ao desenho direção e movimento. A fila no primeiro plano, por demais esparsa, forma uma diagonal muito leve, quase paralela à linha de base. ${ }^{33}$

Mas como comparar uma cena de gênero, desenhada com a modesta técnica das estampas populares (image d'Epinal), pintada com aquarela, e cujo título apresenta uma inflexão irônica, com a pintura de história a óleo, que traz em grandes telas os temas caros aos republicanos franceses?

Vemos nessa aquarela, e em inúmeras ilustrações de Viagem pitoresca e histórica ao Brasil, não apenas a distância entre o modelo francês da "virtude guerreira" antiga e sua realização no Brasil, mas a busca por novos padrões de representação que deem conta da realidade de um povo em processo de constituição. É a arte da estampa e da gravura que vai acolher esta experimentação, enquanto seus temas se afirmarão, na pintura romântica, em uma estética que se tornará dominante, a da pintura "orientalista".

As ilustrações de Debret são aquarelas, que, em cenas de gênero, para além do caráter documental, encenam momentos e gestos do cotidiano da população do Rio de Janeiro ou de pequenos trabalhadores do campo. Nas estampas, a construção geométrica do espaço cede sua monumentalidade e se apaga, para destacar figuras que surgem como o rosto popular de uma nação, nos

32. Jean Baptiste Debret. O primeiro impulso da virtude guerreira, 1827. Aquarela sobre papel, $15,2 \times 21,5 \mathrm{~cm}$ - Museu da Chácara do Céu, Rio de Janeiro. (desenho não utilizado na Viagem pitoresca e histórica ao Brasil). Reproduzido em NAVES. A forma difícil; ensaios sobre a arte brasileira, p. 41.

33. NAVES. A forma dificil; ensaios sobre a arte brasileira, p. 41. 
cenários em que vivem, trabalham ou festejam. O traço do artista excede o registro enciclopédico de todos os detalhes materiais que possibilitem um conhecimento completo da realidade brasileira, pois o que é a realidade brasileira, senão um efeito de imaginário? As ilustrações vão dando forma, rosto, corpo, movimento, cor, luz a um povo que, tal como o povo francês, tem que construir sua identidade de Estado-nação. E aqui, passamos do quadro ao livro, da pintura à literatura e do período pós-revolucionário, à instauração de regimes monárquicos liberais.

\section{Mas a pálida ... a loira?... a moreninha?...}

As exigências políticas da modernidade trazem, para cada povo, a necessidade de se construir uma imagem unificadora, nos cenários ou paisagens de sua nação. Esta, marcada na ênfase dos traços físicos e culturais, pode ser localizada nos clichês e caricaturas em que se comparam nacionais. E os exemplos são inúmeros de obras literárias que se abrem com a descrição das personagens, compondo tipos. Destacamos, a título de ilustração, a descrição de três jovens, no primeiro capítulo de $A$ moreninha (1843), considerado o primeiro romance brasileiro. O autor atribui a cada uma das jovens a personificação de uma estética, conferindo a um retrato privado um valor de alegoria:

Que interessante terceto! exclamou com tom teatral Augusto; que coleção de belos tipos!... uma jovem de dezessete anos, pálida... romântica e, portanto, sublime; uma outra loura... de olhos azuis... faces cor-de-rosa... e... não sei que mais; enfim, clássica e por isso bela. Por último uma terceira de quatorze anos... moreninha, que, ou seja, romântica ou clássica, prosaica ou poética, ingênua ou misteriosa, há de, por força, ser interessante, travessa e engraçada; e por conseqüência qualquer das três, ou todas ao mesmo tempo, muito capazes de fazer de minha alma peteca, de meu coração pitorra!... Está tratado... não há remédio... Filipe, vou visitar tua avó. Sim, é melhor passar os dois dias estudando alegremente nesses três interessantes volumes da grande obra da natureza do que gastar as horas, por exemplo, sobre um célebre Velpeau, que só ele faz por sua conta e risco mais citações em cada página do que todos os meirinhos reunidos fizeram, fazem e hão de fazer pelo mundo. ${ }^{34}$

34. MACEDO. A moreninha, p. 17-18. 
A moreninha, "romântica ou clássica, prosaica ou poética", é o tipo brasileiro. A heroína concentra traços tais como a brejeirice, a vivacidade e a inteligência, e parece ser a alma de um cenário paradisíaco, o da "ilha de..." (Ilha dos Amores, hoje Paquetá). Ao cantar a balada do rochedo, que dá voz aos amores da jovem índia tamoia Ahy, Carolina, a moreninha, com ela se confunde. A tensão entre estéticas conflitantes, a clássica, voltada para o belo, ou a romântica, levando ao sublime, no cenário da inocência infantil, perde sua importância e gera uma nova beleza, e esta é brasileira.

Do mesmo modo, cada identidade nacional vai se constituir por contraponto com outras identidades, com as quais vai estabelecer relações de aliança e rivalidades.

Um velho alemão ficava à esquerda dela e, sem vaidade, podia Augusto afirmar que D. Clementina prestava mais atenção a ele que aos jagodes, que, também, a falar a verdade, por seu turno, mais se importava com o copo do que com a moça. ${ }^{35}$

Era por isso que todos brincavam alegremente, menos o Sr. Kleberc que, diante de meia dúzia de garrafas vazias, roncava prodigiosamente; grande alemão para roncar!... era uma escala inteira que ele solfejava com bemóis, bequadros e sustenidos!... dir-se-ia que entoava um hino... a Baco.

Os aspectos etnocêntricos são explícitos. São marcados traços culturais nacionais, que encontramos, por vezes, exagerados nos conflitos por hegemonia de culturas rivais e, nas guerras de 1870, 1914, 1945, nos ódios nacionalistas. As diferenças também podem ser lidas como marcas de desigualdade e desníveis entre etnias, definindo povos superiores e povos inferiores. O que permite conciliar políticas colonialistas com as proclamações de autodeterminação dos povos. Também a título de ilustração, trazemos a apresentação das personagens do Romance da Múmia (1858), de Théophile Gautier.

- Tenho um pressentimento de que, no vale de Biban-el-Molouk, encontraremos um túmulo intacto, dizia a um jovem inglês de expressão altiva um personagem muito mais humilde, enquanto, com um grande

35. MACEDO. A moreninha, p. 39.

36. MACEDO. A moreninha, p. 89. 
lenço quadriculado de azul, enxugava a fronte calva de que pingavam gotas de suor, como se ele tivesse sido modelado a partir de uma argila porosa e contivesse água, como uma talha de Tebas.

- Que Osíris o ouça, respondeu ao doutor alemão o jovem lorde: esta é uma invocação que podemos nos permitir diante da antiga Dióspolis magna; mas já tivemos tantas decepções; os caçadores de tesouros sempre haviam chegado antes de nós.

- Um túmulo que não tenha sido violado nem pelos reis pastores, nem pelos medas de Cambises, nem pelos gregos, pelos romanos, ou pelos árabes e que nos oferecerá suas riquezas intocadas e seu mistério virgem, prosseguiu o cientísta suado, com um entusiasmo que fazia brilharem os olhos, por trás das lentes azuis dos óculos.

- E sobre o qual o senhor publicará uma dissertação das mais eruditas, que lhe dará um lugar, na ciência, ao lado de cientistas como Champollion, Rosselini, Wilkinson, Lepsius e Belzoni, disse o jovem lorde. - Esta dissertação lhe será dedicada, mylord, ela lhe será dedicada: pois sem o senhor que me concedeu um tratamento de real munificência, eu não teria podido corroborar meu sistema com a visita dos monumentos e teria morrido em minha cidadezinha na Alemanha, sem ter podido contemplar as maravilhas desta terra antiga, respondeu o cientista emocionado.

A conversa tinha lugar não longe do Nilo, na entrada do vale de Bibanel-Molouk, entre lorde Evandale, que montava um cavalo árabe, e o doutor Rumphius, mais modestamente montado em um burro, em cujo magro lombo um fellah batia com um bastão (...). Alguns homens da tripulação [do barco que os transportara] acompanhavam mais atrás Lorde Evandale e o doutor Rumphius, enquanto os outros, estendidos no convés à sombra das cabines, fumavam placidamente um cachimbo e tomavam conta da embarcação.

Ao considerarmos as obras literárias, suspendendo o recorte por literaturas nacionais, vemos que o campo literário se constitui com estruturas comparáveis, em diferentes países, sempre em relação com a construção de uma identidade nacional, vinculada a uma legitimidade política e cultural. No Brasil, como na França, a Literatura vem substituir um sistema de gêneros em verso, o das Belas-letras, por gêneros predominantemente em prosa, com a promoção do

37. GAUTIER. Roman de la momie, p. 5-6. 
conto e do romance, até então pouco valorizados, ou a criação de novos gêneros narrativos, como o conto fantástico ou o romance de folhetim. Percebe-se, então, o que esconde em termos de violência simbólica ${ }^{38}$ a díade modelo-cópia, que presidiu, por muito tempo, a leitura das relações entre literatura francesa e literatura brasileira.

O contraste entre Paris, que, em 1800, conta com 500.000 habitantes e o Rio de Janeiro, que teria 60.000 habitantes, quando chega a Corte portuguesa, em 1808, não poderia ser maior. ${ }^{39}$ E o que dizer de um país onde a entrada de livros foi controlada, título por título, e cuja primeira imprensa é trazida em 1808, pelo príncipe português? ${ }^{40}$ Em que pesem as circunstâncias, os traços estruturais de constituição de uma nova ordem política e social, e sua relação com a literatura e as artes, podem ser colocados em perspectiva, uma vez que o Rio de Janeiro, por ser um porto e a capital, encontrava-se integrado a um circuito cosmopolita. ${ }^{4}$

A mesma distância entre Paris e o Rio de Janeiro, em termos populacionais e no que se refere ao desenvolvimento urbano e arquitetônico, pode ser encontrada se compararmos parques editoriais, a capacidade instalada de editar livros com qualidade gráfica ou as dimensões do público leitor. Mas tal distância não deve fazer perder de vista os desafios políticos da constituição do campo literário, que se tornam evidentes se explorarmos a legitimação de temas e gêneros, os novos suportes de publicação, seus modos de circulação, ou suas estratégias para alcançar e ampliar o público leitor.

38. Conceito proposto por Pierre Bourdieu e que se refere a "uma violência não percebida, fundamentada no reconhecimento, obtido por um trabalho de inculcação, da legitimidade dos dominantes pelos dominados, que garante a permanência da dominação". BONNEWITZ. Pierre Bourdieu; vie, oeuvre, concepts, p. 94.

39. Cf. HOBSBAWM. A era das revoluçôes; Europa 1789-1848, p. 426; e NAVES. A forma difícil; ensaios sobre a arte brasileira, p. 67.

40. Cf. NEVES. Antídotos contra obras "ímpias e sediciosas": censura e repressão no Brasil de 1808 a 1824, p. 378.

41. Cf. HOBSBAWM. A era das revoluções; Europa 1789-1848, p. 25-27. 


\section{The cultured Europe and the wonderful desert}

Abstract: The present essay is an approach of the relationship between French literature and Brazilian literature, in light of the existing links between literature and nation, from a modern discursive formation standpoint (Foucault. L'archéologie du savoir). National literatures appear into wordly literature space where they follow the same competion rules as those which regulate nations' relationships. Although political and economical processes of Brazilian territorial populating and occupation are not to be compared with the processes that occurred in France, literature may be seen in both countries as a system that produces and puts into circulation new forms of symbolic capital, imaginary identifications and hegemonical linguistic patterns. French Mission is mentionned to recall its true meaning of educating eyesight. A description of characters will be also considered in their function of producing and enhancing an image of national typical persons.

Keywords: National Literatures, Romanticism, French Mission.

$$
\text { Referências }
$$

BONNEWITZ, Patrice. Pierre Bourdieu; vie, oeuvre, concepts. Paris: Ellipses, 2002.

CARDOSO, Rafael et al. Castro Maya colecionador de Debret. São Paulo: Capivara; Rio de Janeiro: Fundação Castro Maya, 2003. p. 29.

CASANOVA, Pascale. La République Mondiale des Lettres. Paris: Seuil, 1999.

Charaudeau, Patrick; MAINGUENEAU, Dominique. Dictionnaire d'analyse du discours. Paris: Seuil, 2002.

CHARTIER, Roger. Leituras e leitores na França do Antigo Regime. Trad. Álvaro Lorencini. São Paulo: UNESP, 2003.

DEBRET, Jean-Baptiste. Voyage pittoresque et historique au Brésil, III, Paris: Firmin Didot Frères, 1839.

FOUCAULT, Michel. Les mots et les choses. Paris: Gallimard, 1966.

FOUCAULT, Michel. L'archéologie du savoir. Paris: Gallimard, 1969.

GAUTIER, Théophile. Roman de la momie. Paris: Hachette, 1858. Disponível em: <http://www.ebooksgratuits.com>. Acesso em: 23 fev. 2009.

GUIMARÃES, Samuel Pinheiro. Quinhentos anos de periferia. Porto Alegre/Rio de Janeiro: Editora UFRGS/Contraponto, 2002.

HOBSBWAM, Eric J. A era das revoluções; Europa 1789-1848. Trad. Maria Tereza Lopes Teixeira e Marcos Penchel. São Paulo: Paz e Terra, 2008a. 
HOBSBWAM, Eric. Nações e nacionalismo desde 1870. Trad. Maria Célia Paoli e Anna Maria Quirino. Rio de Janeiro: Paz e Terra, 2008b.

LE GOFF, Jacques. Em busca da Idade Média. Trad. Marcos de Castro. Rio de Janeiro: Civilização Brasileira, 2006.

LÉVI-STRAUSS, Claude. Tristes tropiques. Paris: Plon, 1955.

LUZ, Angela Ancora da. Missão francesa. Disponível em: <http://www.eba.ufrj.br/ $\sim$ missaofrancesa>. Acesso em: 4 jul. 2007.

MACEDO, Joaquim Manoel de. A moreninha. São Paulo: Martin Claret, 2003.

MAINGUENEAU, Dominique. Formation discursive. In: CHARAUDEAU, Patrick; MAINGUENEAU, Dominique. Dictionnaire d'analyse du discours. Paris: Seuil, 2002a. p. 271.

MAINGUENEAU, Dominique. Interdiscours. In: CHARAUDEAU, Patrick; MAINGUENEAU, Dominique. Dictionnaire d'analyse du discours. Paris: Seuil, 2002b. p. 324.

MAINGUENEAU, Dominique. Archéologie et analyse du discours. Texto! Juin 2005. Disponível em: <http://www.revue-texto.net/Reperes/Themes/ Maingueneau_Archeologie.html>. Acesso em: 27 jan. 2009.

MELLO, Celina Moreira de. Por um novo olhar sobre um saber antigo; o estatuto do clássico no espaço-histórico francês. Calíope Presença Clássica. 7 Letras \& Programa de Pós-graduação em Letras Clássicas/UFRJ, n. 14, p. 39-56, 2006.

MELLO, Celina Moreira de. L'Artiste (1831-1838); crítica literária, ethos e cena genérica. III SIMPÓSIO INTERNACIONAL SOBRE ANÁLISE DO DISCURSO; EMOÇÕES, ETHOS E ARGUMENTAÇÃO. Anais... Belo Horizonte, UFMG, 2008. CD-ROM

NAVES, Rodrigo. A forma difícil; ensaios sobre a arte brasileira. 2. ed. São Paulo: Ática, 2001.

NEVES, Lúcia Maria Bastos. Antídotos contra obras "ímpias e sediciosas": censura e repressão no Brasil de 1808 a 1824. In: ABREU, Márcia (Org.). Leitura, história e bistória da leitura. Campinas: Mercado de Letras, 2000. p. 377-410.

NITHEROY; Revista Brasiliense. Sciencias, Letras e Artes. Paris, t. I, n.1 e 2, 1836.

SAND, Schlomo. Comment le peuple juif fut inventé; de la Bible au sionisme. Traduzido do hebraico por Sivan Cohen-Wiesenfeld e Levana Frenk. Paris: Fayard, 2008.

SANTOS, Afonso Marques dos. A Academia Imperial de Belas Artes e o Projeto civilizatório do Império. In: PEREIRA, Sonia Gomes et al. 180 Anos de Escola de Belas Artes. Rio de Janeiro: UFRJ, 1998. p. 127-146. 